\title{
Design and Implementation of a Communication System and Device Aimed at the Inclusion of People with Oral Communication Disabilities
}

\author{
Dr. Máximo López Sánchez \\ Computer Science \\ Cenidet-TecNM \\ Cuernavaca, Mexico \\ Dr. Juan Gabriel González Serna
Computer Science
Cenidet-TecNM
Cuernavaca, Mexico
}

\author{
José Luis Molina Salgado \\ Computer Science \\ Cenidet-TecNM \\ Cuernavaca, Mexico \\ Melisa Hernández Salinas
Computer Science
Cenidet-TecNM
Cuernavaca, Mexico
}

arms or hands, together total $36.4 \%$, while bathing, dressing, eating, talking or communicating, add up to $21.2 \%$ [3].

\begin{abstract}
Disability is part of human condition; it discriminates people who have this complication. The present work was carried out due to this and an experience in our research center. A prototype was designed and build that allows eye signals to be sent to a mobile device, where through a computer system, it was possible to generate an appropriate dialogue mechanism to respond to this challenge. The results allow us to open up an area of opportunity for a contribution in the inclusion of people with disabilities.
\end{abstract}

Keywords-Communication; system; disabilities; device; oral

\section{INTRODUCTION}

Disability is a part of human condition: almost all people suffer some sort of passing or permanent disability at some point in their life, and those who reach senility will experience growing functioning difficulties in their organism, which in many cases causes contact loss with their familiar environment, just as in the case of young people, the critical mass is no longer used due to the fact that they have no way of communicating their knowledge.

Information from the World Health Organization in a 2010 report estimates that over one billion people live with some form of disability. According to the World Health Survey, about 785 million people, (15.6\%), aged 15 and over live with a disability. It shows that, out that of the estimated total of people with disabilities, 110 million, $(2.2 \%)$, have very significant functioning difficulties [1].

On the other hand, the prevalence of disability in Mexico in 2014 was 6\%, according to [2], (National Survey of Demographic Dynamics 2014), information. This means that 7.1 million of the country's inhabitants cannot or find it very difficult to do any of the evaluated activities. Reported disabilities: concentrate $42.4 \%$ (walk, walk up or down using their legs and seeing, even when wearing glasses); learning, remembering or concentrating, listening and moving or using
It's important to mention that during the 2014-2016 period, a student with oral communication problems attended his master's degree program at CENIDET - TecNM, (National Centre for Research and Technological Development National Technological of Mexico), experimenting with his own disability during his research of Master's Thesis.

\section{RELATED WORKS}

Some computer systems, that help people with speech problems to communicate with the people in their environment, were checked. These are: 1) Verbo [4]. It is a software that can be installed in computers with Windows or Android operating systems and can be adapted to different pushbutton devices such as special keyboards, keypads, and eyepieces among others. The user constructs the phrase he/she wishes to communicate using pictograms. Another similar system is 2) IRISBOND [5]. That can be used by people suffering from ALS (atherosclerosis), spinal cord injury, paraplegia or other conditions, thanks to the implementation of an ocular tracking technology with which the user can manipulate the different systems installed on Windows such as: Facebook, WhatsApp, Microsoft Word, etc., it also incorporates software that allows sentence building through a virtual keyboard. 3) The third option is AraBoard [6]. This allows the creation, edition and use of communication boards for different devices (computers, smartphones or tablets), as well as different operating systems, in this system, users with speech problems structure their messages selecting pictograms. 4) Eyecan [7]. The project was introduced as a mouse that is controlled by sight and together with a virtual keyboard quadriplegic users can write messages to communicate. 5) Alternative communication system for people with cerebral paralysis who can read and write with the support of an Android mobile device [8]. It 
proposes the use of an Arduino made button and software that installs on a mobile device running Android, which uses a virtual keyboard where the user selects one by one the letters or words that make up the phrase that he wants to express one by one to ease letter selection, a swipe on the keyboard, first vertical and then horizontal, is made, stops are indicated via a button that adapts to the user's mouth and is activated by means of oral muscle movement. 6) Lastly, alternative and augmentative communication system for people with phonetic problems, with support of an Android mobile device [9] and 7) SAAC - Droid, a tool to help communication [10]. They are systems that are installed on Android devices and use touchscreens. The first structure dialogues through pictogram selection, while the second uses a virtual keyboard. Users of these systems must have mobility in upper limbs that allows device use. Our alternative communication proposal consists of two parts: development of a non-invasive device and a computer system.

\section{DEVICE DEVELOPMENT}

To solve the problem in terms of communication, a methodology was designed, (Fig. 1), which has five activities that range from a current solution search to the implementation of a functional device.

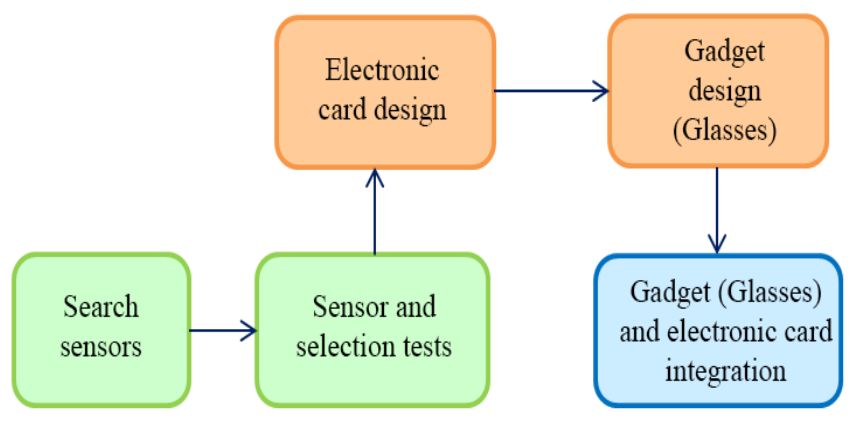

Fig. 1. Methodology.

\section{A. Sensor Search}

In the search for sensors, it was determined that the most adapted option to the solution of our problem were the reflexive optical sensors, due to the fact that people with motor disabilities have limited movements in their body parts, this is, that they have the ability to perform certain hand, finger, head and mainly eye movements. So, we focused our work on this last movement.

Considering this type of sensor, we found that the most relevant ones are the following:

\section{1) $C N Y 70$}

The CNY70 is a short-range infrared sensor based on a light emitter and a receiver, both pointing in the same direction, whose operation is based on object reflection capacity and beam detection reflected by the receiver [11].

\section{2) IR Sharp Sensors}

An Infrared sensors family for object detection offers distance information according to the range in which it receives signals, specifically in the case of the GP2D02 and GP2D12 models. These sensors work through light triangulation, which bounces off an object and according to the distance of that object, the angle tends to differ [12].

\section{3) $Q R D 1114$}

It is an optical sensor composed of an infrared diode and a phototransistor, which is responsible for detecting infrared light reflection. In general, its use achieves light change detection in black and white colors; its measurement range is between 0.5 to 1 centimeters [13].

\section{4) $\mathrm{TSOP} 4838$}

It is an infrared sensor used to receive infrared signals from remote controls; they are normally used in home appliances. The sensor has an amplifier circuit and a $38 \mathrm{Khz}$ oscillator inside, which allows signal reception even in the presence of intense light sources [14].

\section{5) Diode Emitter and Phototransistor}

The IR LED (emitter diode) is responsible for emitting a sort of electromagnetic radiation better known as infrared light. The phototransistor differs from a common transistor because its base has been replaced by a photosensitive crystal that regulates the flow of collector-emitter current according to the light shed on it [15].

\section{6) TCRT5000 and TCRT5000L}

The TCRT5000 and TCRT5000L are reflective sensors that include an infrared emitter and a phototransistor in a lead pack that blocks visible light. The package includes two mounting clips [16].

\section{B. Sensor Selection}

So as to select the right sensor for our solution we considered the following points:

- Size: Size was considered because the sensor will be used for eye blinking detection without obstructing the user's vision.

- Distance detection: This variable was taken into account, since the sensor must detect eye blinking, thus, it must be at a certain distance from the eyewear lens to the user's eye.

- Operational voltage: an adequate voltage was taken into account due to the characteristics of device operation and the energy expenditure it represents.

- Response time: It was considered because response speed is required to be as fast as possible.

From these characteristics, the following comparative table was obtained (Table 1), where each of the features are analyzed and from which the best suited sensor for the job was selected. 
TABLE I. COMPARATIVE TABLE (SENSORS)

\begin{tabular}{|c|c|c|c|c|}
\hline \multirow[b]{2}{*}{ Sensor } & \multicolumn{4}{|l|}{ Characteristics } \\
\hline & Dimensions & $\begin{array}{l}\text { Range } \\
\text { detection }\end{array}$ & $\begin{array}{l}\text { Operation } \\
\text { Voltage }\end{array}$ & $\begin{array}{l}\text { Response } \\
\text { time }\end{array}$ \\
\hline CNY70 & $7 \times 7 \times 6 \mathrm{~mm}$ & $<.5 \mathrm{~mm}$ & $5 \mathrm{~V}$ & \\
\hline GP2D02 & $37 \times 14 \times 14.4 \mathrm{~mm}$ & $\begin{array}{l}10 \text { a } 80 \\
\mathrm{~cm} .\end{array}$ & 4.4 a $7 \mathrm{~V}$ & $70 \mu \mathrm{s}$ \\
\hline GP2D12 & $37 \times 14 \times 14.4 \mathrm{~mm}$ & $\begin{array}{l}10 \text { a } 80 \\
\mathrm{~cm} .\end{array}$ & 4.5 a $5.5 \mathrm{~V}$ & $32 \mu \mathrm{s}$ \\
\hline QRD1114 & $\begin{array}{l}6.1 \times 4.39 \times 4.65 \\
\mathrm{~mm}\end{array}$ & $\begin{array}{l}0.050 " \\
(1.27 \\
\mathrm{mm})\end{array}$ & $5 \mathrm{~V}$ & $\begin{array}{l}10 \mu \mathrm{s}, 50 \\
\mu \mathrm{s}\end{array}$ \\
\hline TSOP4838 & $3 \mathrm{~cm} \times 0,5 \mathrm{~cm}$ & $35 \mathrm{~m}$ & 3 a $6 \mathrm{~V}$ & $9 \mu \mathrm{s}$ \\
\hline $\begin{array}{l}\text { Emitting Diode } \\
\text { and } \\
\text { Phototransistor }\end{array}$ & 5 y $3 \mathrm{~mm}$ & ---- & 3 a $5 \mathrm{~V}$ & ----- \\
\hline TCRT5000L & $\begin{array}{l}10.2 \times 5.8 \times 7 \\
\mathrm{~mm}\end{array}$ & $2.5 \mathrm{~mm}$ & $5 \mathrm{~V}$ & $10 \mu \mathrm{s}$ \\
\hline
\end{tabular}

\section{Electronic Card Design}

For the electronic card design, two PCB (Printed Circuit Board) design software were used, these are:

\section{1) PCB Wizard}

It is an educational area designed program, which allows electronic circuit schematics creation and thus easily obtain one or two-sided printed circuit designs [17].

\section{2) Fritzing}

It was created under the Processing and Arduino principles, allowing designers to document their prototypes based on Arduino and create printed circuit diagrams for later manufacture.

It is an open source software and has libraries with the majority of components that include the Arduino ones, connection boards, LED, motors, displays, among others [18].

\section{Gadget Design (Glasses)}

Within this stage a previous analysis was carried out on some commercial glasses type devices to take into account size, weight, ergonomics and materials used in them.

The analyzed devices are the following:

- Google Glass [19].

- Epson Moverio bt-200 [20].

- Wink Glasses mod. 2013 [21].

- Glassup [22].

- Vuzix Smarth Glasses [23].

For gadget modeling, AutoCAD software, which provides tools to develop 3D models, was used.

Development steps were as follows:

- A first pencil sketch was designed (Fig. 2).

- The first sketch was modeled in AutoCAD (Fig. 3).

- The 3D model was printed.

- The reflective optical sensors were placed on the lens of the glasses.
- The design was modified due to the tests performed with the sensors (Fig. 4).

- A final prototype was established (Fig. 5).

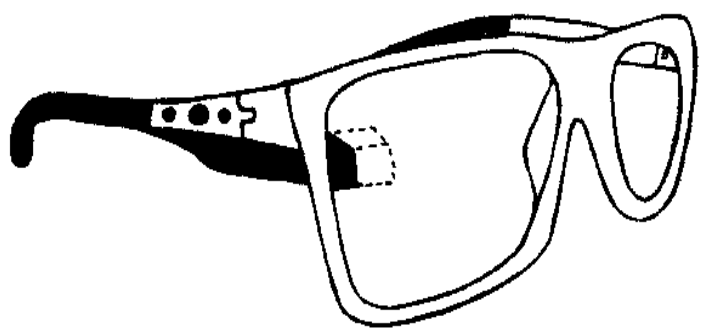

Fig. 2. First pencil sketch glasses.

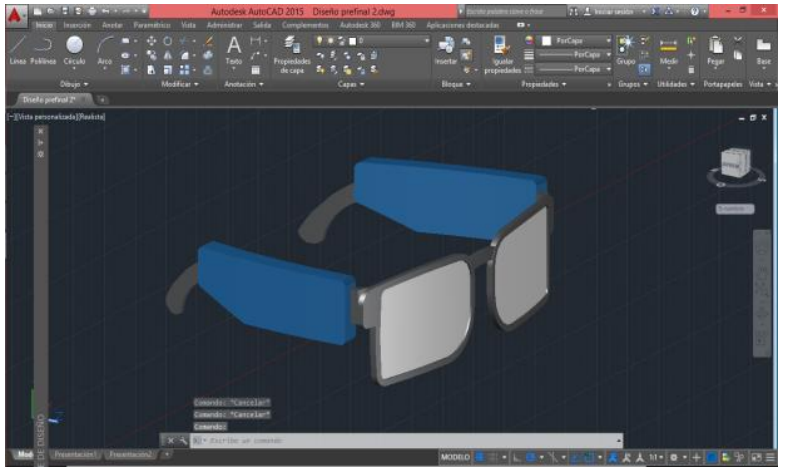

Fig. 3. First sketch in AutoCAD.

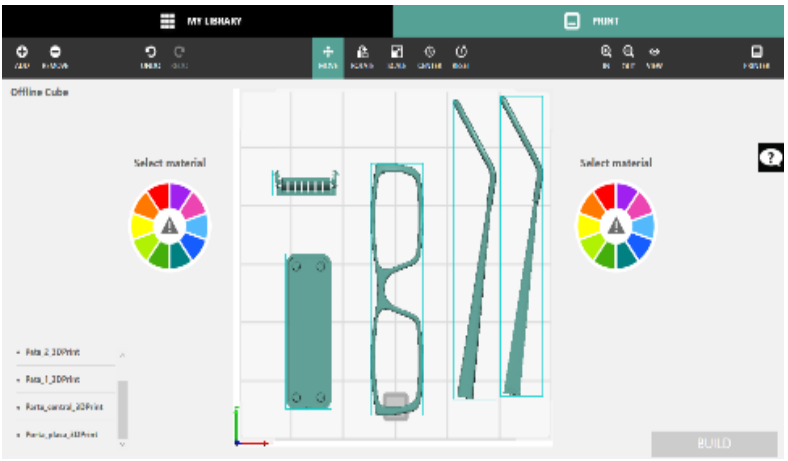

Fig. 4. Second design seen from the Cube Print platform ready for printing.

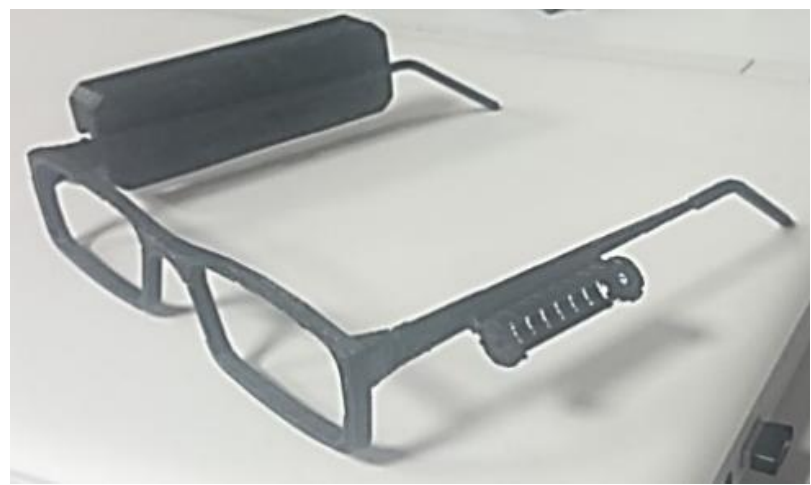

Fig. 5. Final prototype. 


\section{E. Electronic Card and Gadget Integration}

Once the lens was printed, the electronic card was inserted inside the plate holder, which is placed on the right side of the glasses and the corresponding connections to the battery holder, placed on the left side, were made, so as to finally have a functional prototype which integrates all the parts to fulfill their integral function.

To obtain better sensor readings, these must have a calibration function, so that the detected information received from the sensors is adapted to the characteristics of the user. For this, tests were carried out to verify reading efficiency in sunlight, white LED and dark environments (Table 2).

Once the gadget is duly integrated, data detected by the sensor is sent wirelessly to a system where it is converted to letters, so that later on the user can form words and thus establish communication with people in their environment.

Environment 1 = Environment with sunlight

Environment 2 = White led light

Environment 3 = Darkness

TABLE II. EXPOSURE OF SENSORS TO DIFFERENT ENVIRONMENTS

\begin{tabular}{|l|l|l|l|}
\hline User & Environment 1 & Environment 2 & Environment 3 \\
\hline 1 & $10 / 10$ & $10 / 10$ & $10 / 10$ \\
\hline 2 & $10 / 10$ & $10 / 10$ & $10 / 10$ \\
\hline 3 & $10 / 10$ & $10 / 10$ & $10 / 10$ \\
\hline 4 & $7 / 10$ & $7 / 10$ & $7 / 10$ \\
\hline 5 & $10 / 10$ & $10 / 10$ & $10 / 10$ \\
\hline 6 & $10 / 10$ & $10 / 10$ & $10 / 10$ \\
\hline 7 & $10 / 10$ & $10 / 10$ & $10 / 10$ \\
\hline 8 & $10 / 10$ & $10 / 10$ & $10 / 10$ \\
\hline 9 & $10 / 10$ & $10 / 10$ & $10 / 10$ \\
\hline 10 & $10 / 10$ & $10 / 10$ & $10 / 10$ \\
\hline Percentage & $\mathbf{9 7 \%}$ & $\mathbf{9 7 \%}$ & $\mathbf{9 7 \%}$ \\
\hline
\end{tabular}

It should be noted that for these trials, tests were made on 10 people aged between 22 to 28 , who were not necessarily disabled, and each user was told to blink 10 times to determine the amount of blinks detected by the sensors, and based on this, know if the sensor position calibration in the lens of the gadget was correct.

\section{APPLICATION (SOFTWARE)}

A computer system was developed to use the device with a mobile, it is able to communicate wirelessly with the device in charge of sending the user's signals, allows obtained information gathering based on user blinking by executing actions such as: write a letter, predict a word, formulate sentences and interpret in a sonorous way what the user writes. The developed system consists of:

- Wireless communication module.

- Data transformation algorithm.

- Dictionaries.

- Interpretation algorithm.
- Matching algorithm.

- Audio playback module.

\section{A. Wireless Communication Module}

The system makes use of the computer device's wireless technologies on which it is installed; this system is compatible with Wi-Fi or Bluetooth communication.

"Bluetooth ${ }^{\circledR}$ is a low-power wireless connectivity technology used to stream audio, transfer data and broadcast information between devices." [24].

"Wi-Fi is a wireless networking protocol that allows devices to communicate without Internet cables. It is technically an industry term that represents the type of wireless local area network (LAN) protocol based on the 802.11 IEEE network standards." [25].

Technologies such as Bluetooth and Wi-Fi are ideal for a system that requires communication at a distance no greater than 10 meters; in addition, these technologies are quite common in everyday computing devices.

The system is programmed to send and receive information from the signal detection device, so that the data can be obtained in real time and does not depend on the complementary use of some other type of technology. Fig. 6 shows a schematic of the module composition.

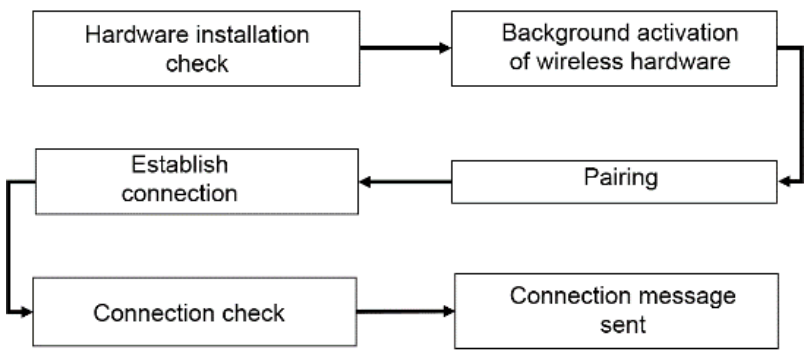

Fig. 6. Connection module.

\section{B. Data Transformation Algorithm}

The system has a module responsible for transforming data that is received from the device, this data is entered into different variables to be processed and know what instructions the user wants executed. The module is in charge of identifying the instruction taking into account the time that elapses between the sending of the signals coming from the device and where the obtained signals take values from $\mathrm{A}$ and $\mathrm{B}$.

The listed instructions are executed according to data reception time, where: Instruction 1 (i1), Instruction 2 (i2) ... Instruction $\mathrm{n}$ (in), are established by knowing the time (t) in milliseconds (ms) that exists between receiving a value $A(t 1)$ with a value $B(t 2)$.

The instructions are executed if and only if:

1) $i 1$

2) $i 2$

$$
100 \mathrm{~ms}<\mathrm{t} 1-\mathrm{t} 2<=1000 \mathrm{~ms}
$$

$1000 \mathrm{~ms}<t 1-t 2<=2000 \mathrm{~ms}$ 
3) $i 3$

$$
\text { 4) in } \begin{aligned}
2000 \mathrm{~ms} & <\mathrm{t} 1-\mathrm{t} 2<=3000 \mathrm{~ms} \\
\mathrm{nms} & <\mathrm{t} 1-\mathrm{t} 2<=\mathrm{nms}
\end{aligned}
$$

The following shows the work scheme of the data transformation algorithm (Fig. 7).

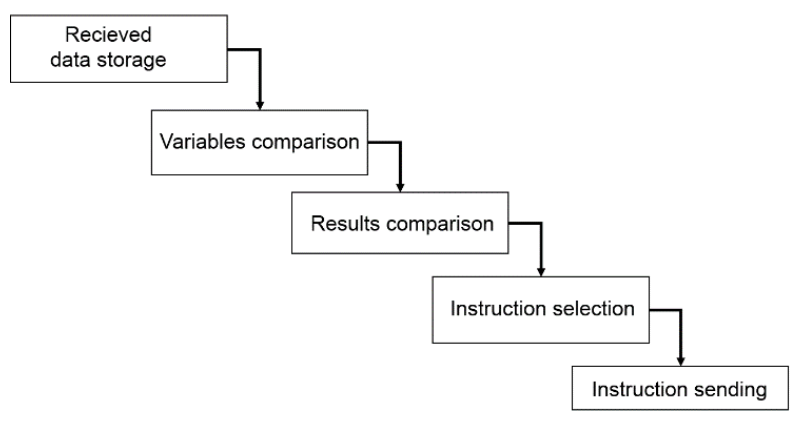

Fig. 7. Data transformation algorithm.

\section{Dictionaries}

The system has three types of dictionaries, General, Temporal and Custom, which are used for storing relevant information, (words), that will be used by the user, making their writing easier (Fig. 8).

"A Data Dictionary is a collection of names, definitions, and attributes about data elements that are being used or captured in a database, information system, or part of a research project. It describes the meanings and purposes of data elements within the context of a project, and provides guidance on interpretation, accepted meanings and representation [26].

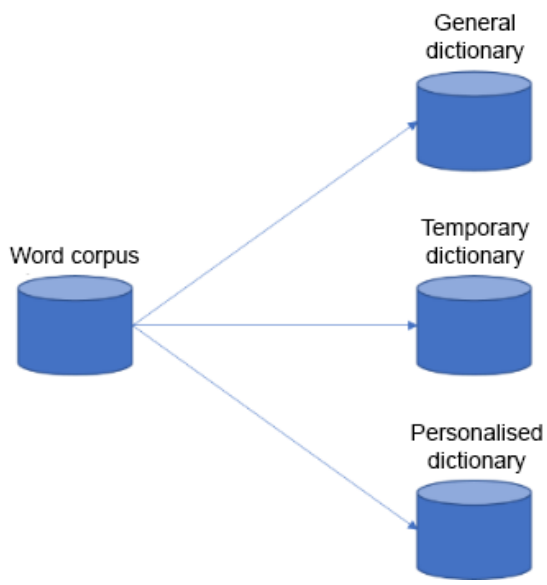

Fig. 8. Corpus and dictionaries.

At first the general dictionary was composed of a corpus of the most used words in Spanish and is available on the official website of the Royal Spanish Academy [27], this information is the basis for custom and temporary dictionary creation, (Fig. 9). Later the English language was added, and it is intended to incorporate as many languages as necessary.

\section{Interpretation Algorithm}

"Morse code is a code or communication system that allows telegraphic communication through the transmission of electrical impulses of various lengths or by visual means, such as light, sound or mechanics. This code consists of a series of points; stripes and spaces, which when combined together can form words, numbers and other symbols" [28].

Within the system, Morse code allows anyone in the world to make use of it, since implemented Morse code is the international version; it has a great variety of numbers, symbols and letters that adapt to most languages.

According to instructions received from the data transformation algorithm, character writing can be established in Morse code, considering points and lines for word and sentence generation. The international Morse code also allows

\begin{tabular}{|c|c|c|c|c|c|c|c|}
\hline \multicolumn{8}{|c|}{ International Morse Code } \\
\hline a & $\bullet-$ & $\mathrm{n}$ & $-\bullet$ & á & $\bullet--\bullet-$ & 8 & $---\bullet \bullet$ \\
\hline b & $-\bullet \bullet \bullet$ & o & --- & ä & $\bullet-\bullet-$ & 9 & $---\bullet$ \\
\hline c & $-\bullet-\bullet$ & $\mathrm{p}$ & $\bullet--\bullet$ & é & $\bullet \bullet-\bullet \bullet$ & 0 & ---- \\
\hline d & $-\bullet$ & $q$ & $--\bullet-$ & $\tilde{n}$ & $--\bullet--$ & , & 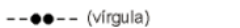 \\
\hline e & • & & $\bullet-\bullet$ & ö & $--\bullet$ & $\therefore$ & $\bullet-\bullet-\bullet-$ \\
\hline$f$ & $\bullet \bullet-\bullet$ & & 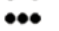 & ü & $\bullet \bullet--$ & ? & $\bullet \bullet--\bullet \bullet$ \\
\hline $\mathrm{g}$ & $--\bullet$ & & - & 1 & $\bullet---$ & ; & $-\bullet-\bullet-\bullet$ \\
\hline $\mathrm{h}$ & $\bullet \bullet \bullet \bullet$ & u & $\bullet \bullet-$ & 2 & $\bullet \bullet---$ & : & $---\bullet \bullet \bullet$ \\
\hline $\mathrm{i}$ & $\bullet$ & $\mathrm{v}$ & $\bullet \bullet \bullet-$ & 3 & $\bullet \bullet \bullet--$ & . & $\bullet---\bullet$ (apóstrofo) \\
\hline j & $\bullet---$ & w & $\bullet--$ & 4 & $\bullet \bullet \bullet \bullet-$ & - & $-\bullet \bullet \bullet$ - (hiffen) \\
\hline $\mathrm{k}$ & $-\bullet-$ & $x$ & $-\bullet \bullet-$ & 5 & $\bullet \bullet \bullet \bullet \bullet$ & I & $-\bullet \bullet-\bullet$ \\
\hline 1 & $\bullet-\bullet \bullet$ & y & $-\bullet--$ & 6 & $-\bullet \bullet \bullet \bullet$ & ( & - $\bullet-\bullet$ (parêntese esquerdo) \\
\hline $\mathrm{m}$ & -- & $\mathrm{z}$ & $--\bullet \bullet$ & 7 & $--\bullet \bullet \bullet$ & ) & 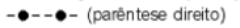 \\
\hline
\end{tabular}
the user to write with a single alphabet in different languages. Fig. 9 shows the code used in the system.

Fig. 9. Morse code (Daisy, 2017).

\section{E. Matching Algorithm}

This algorithm is in charge of using and manipulating different dictionaries, when an alphabetic character written by the user is presented, the algorithm makes an input data selection to find one or more word matches that can be used by the user, if the user wants to write a word of two or more characters, the algorithm receives as input a single character that serves as an indicator to perform the search for a suggestion.

The word matches can be defined as:

- $\mathrm{C}=$ Initial character

- $\mathrm{P}=$ Word of the dictionary

- $\mathrm{Pc}=$ Complement of the word $=\mathrm{P}-\mathrm{C}$

Thus,

- $\mathrm{Co}=$ Coincidence $=\mathrm{C}+\mathrm{Pc}$

Subsequently a selection of suggestions considered as foremost is made, based on all coincidences found in dictionaries and evaluating the nominal frequency of the corpus of words, to obtain the words with greater use probability in the selected language. Fig. 10 is a graphical representation of the matching algorithm operation. 


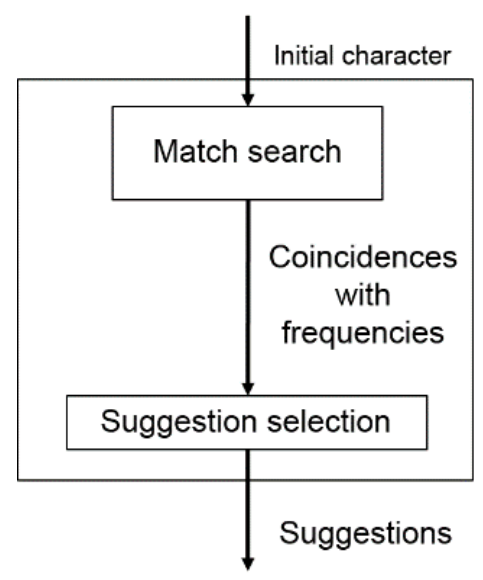

Fig. 10. Matching algorithm.

\section{F. Audio Playback Module}

To reproduce in a sonorous way the texts elaborated or prepared by the user, the system has a text to voice conversion module, to achieve this, it uses tools provided by Google. This module is responsible for storing the textual information in an $\mathbf{O}$ variable and passing it as a parameter to a process that executes the audio playback tools so that the user and the people around him can listen to the previously written messages.

\section{TESTS}

For testing we relied on the "Con Nosotros" foundation, which specializes in basic education of people with cerebral paralysis. Test reactions were applied to enrolled students at the institution.

A test plan was built to validate the system; this consisted of three phases where an evaluation of each phase was carried out.

The first phase aimed to enable the user to identify the precise interpretation time of each selected option. They were asked to practice at least ten actions for each of the available options. The results were evaluated and if at least $70 \%$ of successful values were obtained, the second phase would proceed; Table 3 shows the results obtained.

TABLE III. SELECTED OPTIONS TABLE

\begin{tabular}{|l|l|l|l|}
\hline User & Point & Dash & $\begin{array}{l}\text { Selection } \\
\text { mark }\end{array}$ \\
\hline 1 & $10 / 10$ & $10 / 10$ & $10 / 10$ \\
\hline 2 & $10 / 10$ & $10 / 10$ & $10 / 10$ \\
\hline 3 & $9 / 10$ & $8 / 10$ & $7 / 10$ \\
\hline Average & $9.6 / 10$ & $9.3 / 10$ & $9 / 10$ \\
\hline Percentage & $\mathbf{9 6 . 6 \%}$ & $\mathbf{9 3 . 3 \%}$ & $\mathbf{9 0 \%}$ \\
\hline
\end{tabular}

As can be seen in Table 3, users 1 and 2 results were $100 \%$, unlike user 3, since the latter suffered slight involuntary head movements, which prevented him from maintaining his head position in a single place, as a result of this, the inclination of his head created a shadow that didn't allow continuous light illumination in the controlled environment, that is why the signals obtained by the sensors placed in the gadget didn't have correct eye blinking detection.

The second phase aimed to enable the user to select a button in the application interface. The test in this phase consisted in asking the user to select three buttons that had been previously determined, ten times, these were located in different places on the interface, they had to make seven attempts at pressing each button correctly so that this test could be successfully completed. The results of this test can be seen in Table 4.

TABLE IV. SECOND PHASE RESUlTs

\begin{tabular}{|l|l|l|l|}
\hline User & Button “A" & Button “R” & Button “Z” \\
\hline 1 & $10 / 10$ & $10 / 10$ & $10 / 10$ \\
\hline 2 & $10 / 10$ & $10 / 10$ & $10 / 10$ \\
\hline 3 & $7 / 10$ & $9 / 10$ & $9 / 10$ \\
\hline Average & $9 / 10$ & $9.66 / 10$ & $9.66 / 10$ \\
\hline Percentage & $\mathbf{9 0 \%}$ & $\mathbf{9 6 . 6 \%}$ & $\mathbf{9 6 . 6 \%}$ \\
\hline
\end{tabular}

Lastly, in the third phase, a full use of the application was made. The test consisted in asking the user to write longer phrases, which were made up of more than three words and would then be reproduced using a speech synthesizer; the phrases that were used for the tests are shown in Table 5:

TABLE V. PHRASES

\begin{tabular}{|l|l|}
\hline No. & Phrase \\
\hline 1 & Hello, good day \\
\hline 2 & My name is "User name" \\
\hline 3 & My favorite food is "User's Favorite Food" \\
\hline
\end{tabular}

Test results were:

As can be seen in Table 6 , users 1 and 2 correctly completed any of the 3 sentences, while user 3 , due to the involuntary movements of his head, failed to coordinate the movement of his eyes to select the desired button.

As for the average writing times, writing each sentence in ten tries was considered, taking the average time of the first five attempts and the last five attempts. Tables 7 and 8 shows the results obtained.

TABLE VI. COMPLETED PHRASES

\begin{tabular}{|l|l|l|l|}
\hline User & $\begin{array}{l}\text { Phrase } \\
\mathbf{1}\end{array}$ & $\begin{array}{l}\text { Phrase } \\
\mathbf{2}\end{array}$ & $\begin{array}{l}\text { Phrase } \\
\mathbf{3}\end{array}$ \\
\hline 1 & $10 / 10$ & $10 / 10$ & $10 / 10$ \\
\hline 2 & $10 / 10$ & $10 / 10$ & $10 / 10$ \\
\hline 3 & $10 / 10$ & $8 / 10$ & $7 / 10$ \\
\hline Average & $10 / 10$ & $9.3 / 10$ & $9 / 10$ \\
\hline Percentage & $\mathbf{1 0 0 \%}$ & $\mathbf{9 3 . 3 \%}$ & $\mathbf{9 0 \%}$ \\
\hline
\end{tabular}

TABLE VII. FIRST FIVE ATTEMPTS

\begin{tabular}{|l|l|l|l|}
\hline User & $\begin{array}{l}\text { Elapsed time in } \\
\text { phrase 1 }\end{array}$ & $\begin{array}{l}\text { Elapsed time } \\
\text { in phrase 2 }\end{array}$ & $\begin{array}{l}\text { Elapsed time in } \\
\text { phrase 3 }\end{array}$ \\
\hline 1 & 6.46 & 8.09 & 8.19 \\
\hline 2 & 8.55 & 9.33 & 9.56 \\
\hline 3 & 10.57 & 11.37 & 12.51 \\
\hline Average & $\mathbf{8 . 4 9}$ & $\mathbf{9 . 4 6}$ & $\mathbf{1 0 . 2 2}$ \\
\hline
\end{tabular}


TABLE VIII. LAST FIVE ATTEMPTS

\begin{tabular}{|l|l|l|l|}
\hline User & $\begin{array}{l}\text { Elapsed time in } \\
\text { phrase 1 }\end{array}$ & $\begin{array}{l}\text { Elapsed time in } \\
\text { phrase 2 }\end{array}$ & $\begin{array}{l}\text { Elapsed time } \\
\text { in phrase 3 }\end{array}$ \\
\hline 1 & 1.21 & 2.12 & 2.1 \\
\hline 2 & 2.07 & 3.04 & 4.03 \\
\hline 3 & 2.27 & 6.24 & 10.07 \\
\hline Average & $\mathbf{2 . 0 7}$ & $\mathbf{3 . 4 3}$ & $\mathbf{5 . 2 6}$ \\
\hline
\end{tabular}

A reduction of more than 6 minutes for sentences 1 and 2 can be seen, a little more than 4 minutes in sentence 3 .

\section{CONCLUSIONS}

During this project's making, an effective proposal was sought for phrase and sentence writing, it was considered that one way is to obtain input as binary data, so taking into account the availability of Morse code, it was decided to implement a methodology in where its only necessary to select the desired object on the screen, from the first of the row and scroll the objects until you reach the desired element, this way writing time was reduced in the application.

When testing in controlled environments, with users suffering from cerebral paralysis, it was observed that this system is useful only for users who, besides having full control over their blinking, do not present involuntary movements that affect excessively their head position, since when tilting the head down, the sensors enter the shadow generated as a result of this inclination, giving an incorrect eye blinking reading due to this change of light.

However, according to the opinion of the three users the application is simple to use and easy to memorize when looking for a desired letter.

There is an area of improvement in both the device and the computer system and work will continue. On the other hand, there are some limitations to carrying out more tests, due to the fact that because it is often difficult for institutions that tend to this stratum of people to have enough time to apply tests.

\section{ACKNOWLEDGEMENT}

The result of this work was sponsored by cenidet-TecNM

\section{REFERENCES}

[1] WHO, "World Health Organization," [Online]. Available: http://www.who.int/es/. [Last access:25 08 2017].

[2] INEGI, "ENADID," $2014 . \quad$ [Online]. Available: http://www.beta.inegi.org.mx/proyectos/enchogares/especiales/enadid/20 14/. [Last access:20 08 2017].

[3] INEGI, "INEGI," [Online]. Available: http://internet.contenidos.inegi.org.mx/contenidos/productos/prod_serv/c ontenidos/espanol/bvinegi/productos/nueva_estruc/702825090203.pdf. [Last access:20 08 2017].

[4] “eneso," 2017. [Online]. Available: http://www.eneso.es/verbo/. [Last access:21 09 2017].

[5] “irisbond," $2016 . \quad$ [Online]. Available: http://www.irisbond.com/productos/irisbond-duo. [Last access:21 09 2017].
[6] "GIGA," 2015.2 [Online]. Available: http://giga.cps.unizar.es/affectivelab/araboard.html. [Last access:21 09 2017].

[7] “samsung," $2014 . \quad$ [Online]. Available: https://news.samsung.com/global/samsung-electronics-introduceseyecan-next-generation-mouse-for-people-with-disabilities. [Last access:21 09 2017].

[8] J. A. M. Mancilla, Sistema de comunicación alternativa para personas con parálisis cerebral que saben leer y escribir con el apoyo de un dispositivo móvil con Android, 2013.

[9] G. C. Martínez, "Sistema alternativo y aumentativo de comunicación para personas con problemas fonéticos con el apoyo de un dispositivo móvil con Android," 2014.

[10] S. Aguirre, "SAAC-Droid, una herramienta de ayuda a la comunicación.," 2013.

[11] “Carrod electronica," 2014. [Online]. Available: https://www.carrod.mx/products/sensor-reflectivo-de-un-canal-cny70. [Last access:17 09 2017].

[12] "Wiki de robótica," [Online]. Available: http://wiki.robotica.webs.upv.es/wiki-de-robotica/sensores/sensoresproximidad/sensor-infrarrojos/. [Last access:17 09 2017].

[13] "Brico Geek," [Online]. Available: http://tienda.bricogeek.com/sensores/217-sensor-optico-qrd1114.html. [Last access:17 09 2017].

[14] "Cetronic componentes electrónicos," [Online]. Available: http://www.cetronic.es/sqlcommerce/disenos/plantilla1/seccion/producto/ DetalleProducto.jsp?idIdioma $=\&$ idTienda $=93 \&$ codProducto $=84-$ TSOP4838\&cPath=1353. [Last access:17 09 2017].

[15] "Proyectos Electronics," [Online]. Available: https://catorcepi.wikispaces.com/file/view/3678453-SENSORINFRARROJO-Teoria-y-practica.pdf. [Last access:17 09 2017].

[16] “Nano ID,” 2017. [Online]. Available: https://nanoid.mx/products/sensoroptico-reflectivo-infrarrojo-tcrt50001-sin-pcb. [Last access:17 09 2017].

[17] USERS, "Módulo de captura de esquemáticos," de Electrónica práctica, Buenos Aires, redUSERS, 2011, p. 85.

[18] “Fritzing," [Online]. Available: http://fritzing.org/. [Last access:20 09 2017].

[19] "Wikipedia," $309 \quad 2017 . \quad$ [Online]. Available: https://es.wikipedia.org/wiki/Google_Glass. [Last access:20 09 2017].

[20] "EPSON," 2017. [Online]. Available: https://www.epson.es/products/seethrough-mobile-viewer/moverio-bt-200. [Last access:20 09 2017].

[21] T. Hornyak, "Cnet," 1012 2013. [Online]. Available: https://www.cnet.com/news/wink-glasses-fog-up-in-a-flash-forcing-youto-blink/. [Last access:20 09 2017].

[22] "Conéctica," 17 Julio 2013. [Online]. Available: https://conectica.com/2013/07/17/glassup-la-alternativa-economica-paralas-google-glass/. [Last access:20 09 2017].

[23] "Vuzix," 2017. [Online]. Available: https://www.vuzix.com/Products/M100-Smart-Glasses. [Last access:20 09 2017].

[24] Fundation, "Bluetooth," 2109 2017. [Online]. Available: https://www.bluetooth.com/what-is-bluetooth-technology/how-it-works.

[25] M. Pinola, "Lifewire," 1206 2017. [Online]. Available: https://www.lifewire.com/what-is-wi-fi-2377430.

[26] UcMerced, "UcMerced Library," 2508 2017. [Online]. Available: http://library.ucmerced.edu/node/10249.

[27] RAE, "Real Academia Española," 2008 2017. [Online]. Available: http://corpus.rae.es/lfrecuencias.html.

[28] Morse, “Codigo Morse," 1508 2017. [Online]. Available: http://www.codigomorse.com/. 